\section{AERIAL NAVIGATION.}

BY VICTOR TATIN.

The purely mechanical solution of the problem of aerial navigation bas been sought through three means-belicoptera, or large belices with vertical axes, imitation of the natural flight of birds, and aeroplanes moved by helices with horizonial axes.

Helicoptera.-The first belicopteron that was able to sustain itself in the air was that of Lannoy and Bienvenu, and dittes lack to 1784, the epoch at which it was presented to the Academy of Sciences. The vecessary motive power was furnished it by a bow of whalebone. At that time a practical solution was far from being reached, and the apparatus just mentioned awaited improvement for more than tbreequarters of a century. It was then that an ingenious ex perimenter, Mr. A. Penaud, bappily modified it by substituting a twisted rubber thread for the spring. 'This apparatus gave results so superior to those that bad before been obtained that it might almost have passed for a new creation. But despite the efforts of Penaud and a number of ol her investigators, it was impossible to devise any practical result from the beliccpteron, and the little machine became an in teresting playtbing, aud that was an.

The only apparatus of the kind that bas since been constructed is Mr. Forlanini's belicopleron. This experiment was made upon a little larger scale. The springs were re placed by a small and very light steam engine, whose boiler consisied of a vessel filled with water raised to a high temperature. The whole weighed $6 \frac{1}{2}$ pounds, and rose in the air when the engine developed a one fourth borse power, or one horse per 26 pounds. In spite of all the interest that such an experiment presents, we cannot prevent ourselves from remarking that the disposable weight was very feeble in proportion to the considerable work demanded of the engine. Notwitbstanding the contrary opinion of many persons, we sball demonstrate without trouble that we can, by means of a belix, obtain much more favorable results. The experiments which we take for a basis were, like those of

arduous that wo could select in order to reach success with tate the speed of those animals. their very construction, did not possess a maximum of sustainin power. They were not con structed, as in Mr. Forlanini's apparatus, in view of a recoil of abnut 100 per cent. Every helix, in fact, should be carefully studied from the standpoint of what we expect from it. Si, i the belicopteron, as the belix is at the same time a sustainin plane, it should be likened to a surface moving borizontally, and in which, cousequently, the resistince to motion will be to the lifting power as the sinus is to the consinus of the angle formed by such plane with the horizon like belix of sufficiently pirch and of sufficienly short pitcb and of wide sufface, we might theoreticaliy, and by pushing things to the extreme, liftan indefinite weight with a very sligbt power, and we should be limited only by passive resist-

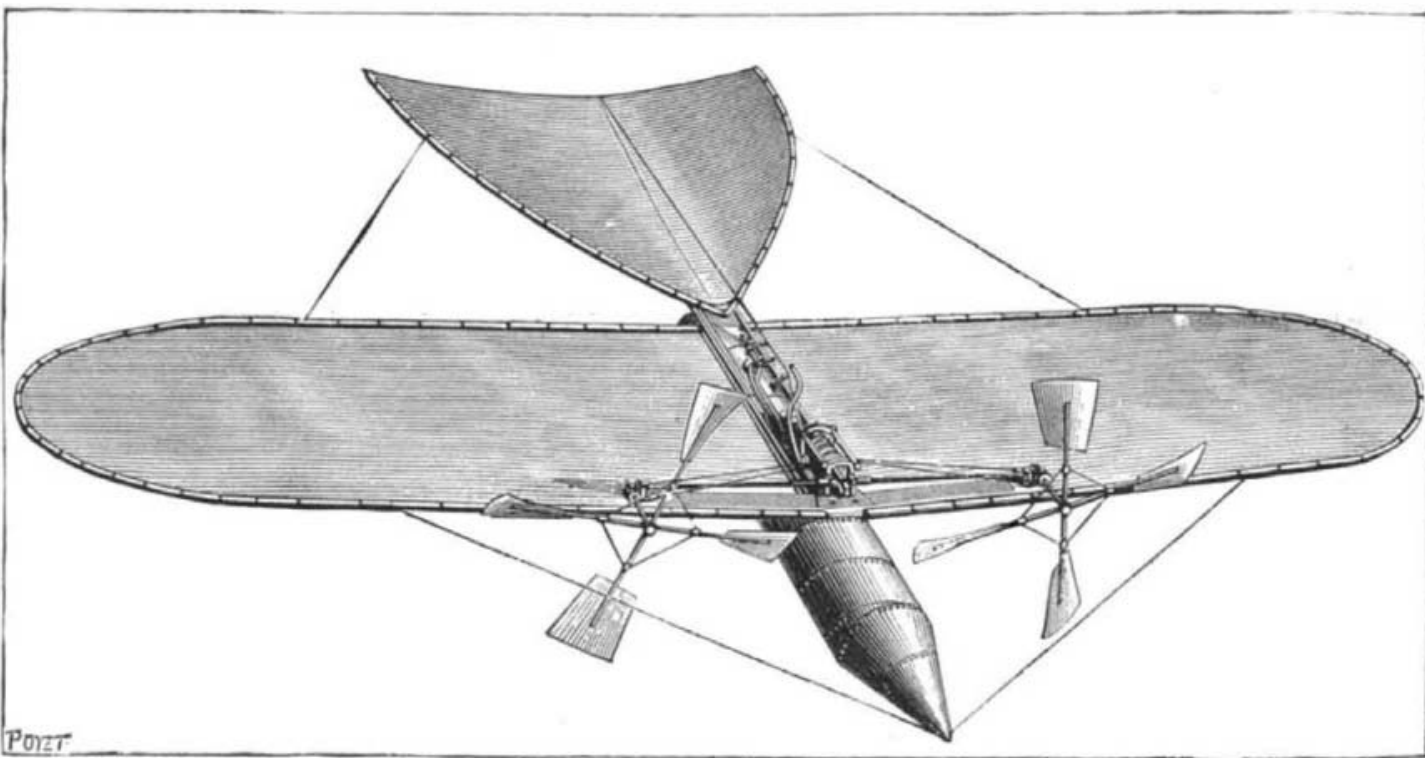

Fig. 2.-TATIN'S AEROPLANE. find a proof of this in some old mythological fables whose gramme up to that of more than a kilogramme, and reachorigin is lost in the deptbs of time. Among the atlempts ing in the latter case a spread of wings of more than two at bave been made since, none bas given a real result, and meters. In our smallest models the rubber spring was

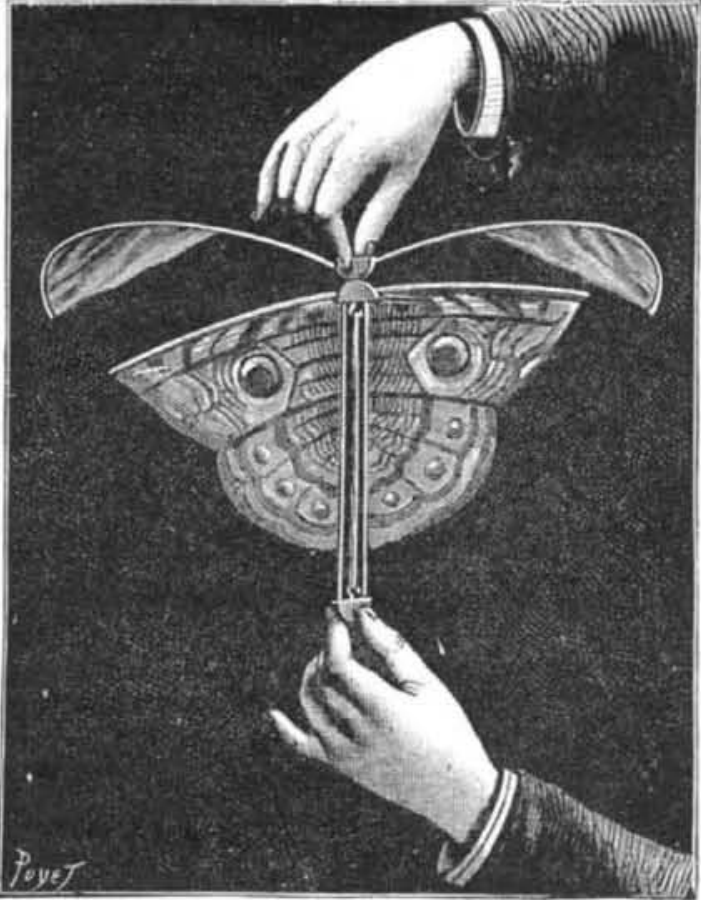

Fig. 1.-TOY HELICOPTERON, the wings ad infinitum, as we did the number and ampliturle be wings ad $i$ fin vantages accompanying the use of wings of birds or cheiroptera, and finally we obtained results that bave never been surpassed, nor even reaclied, hut always by exceeding a power lbat was out of proportinn to the effect obt:ined. We afterward tried to find as exactly as possible the value of this excessive expenditure, by constructing compressed air machices desigaed to replace tbe rubber. nllese apphratus were the largest that we experimented with, and their extreme lightness permitted us to furnish a mecbanical bird vearly ten times its weight in kilogrammes per second.

After modifications without number, and entire or partial reconstructions, the results were so unfortunate that we bad to give up the struggle, at least in this direction. Is that to say that a mechanical bird is a machine impossible to realize? In no wise; we must not conclude from our defeat that better cannot be done, but we sball not advise any une to try it with a view to obtaining a practical result in aeronautics. The very complex motions of a bird's wing during flight are very difficult to imitate in mechanics, and, if nature bas used them, it is because the organs of these animals could not adapt themselves effectively to other and simpler motions that mechanics make use of-rotary motinn, for example. It will he thought, perbaps, that we bave been a pretty bad mechanic. We admit this very willingly, but at present we are convinced by force of time and money that the imitation of nature bas no other interest than that of making us better understaud the means that she employs. It seems to us inadmissible to construct a mechanical bird in order to navitime of Archytas of Tarentum. It is again to Mr. Penaud gate the air. Our fatbers did not try to construct the locothat we owe the first important results in this patl-the most motive after the type of the bare lisbed about them is due to Henson, and dittes back to 1842 only. This, moreover, is the type tbat bas always been reproduced since then. The principle of this apparatus consists in the maintaining in air of a vast plane, to which propelling belices commuuicate a rapid forwilrd motion. No one that we know of bad nbtained gond results by means of these apparatus before Penaud, who ag:tin employed twisted rubber for setting lhese small and astonishingly simple apparatus in motion. This ingenious experimenter unfortunately devised notbing but types of aeroplanes of small dimensions. The disease that was to remove him from us doubtless interfered with his researcbes.

A few years before bis death be published, in conjuncion with one of our friends, $\mathrm{Mr}$. $\mathrm{P}$. ances and fricion. When, on the contrary, the belix in- rubber, caused a small machine to fly, our emulation was |Gauchot, a project for"an aeroplane of large dimensions, but stead of being stationary, or nearly so, is destined to bave excited, and no one perhaps was more entbusiastic than we bis demise prevented its heing carried nut. This construca motion in the direction of its axis, it can be given a longer in the pursuit of a definite result. pitch, since it then attacks the air at an angle that is so mucb During the course of 'our researches, which lasted for seve- but we believe that it we enid baved quite a beavy expense, the smaller in proportion as the recoil is less. It is thus ral months, we constructed a large number of mecbanical the superiority of the aeroplane over all the apparatus that situated under as favorable circumstances as one with a very birds of all sizes and various weights, from that of half a we have described above At the epoch at which Penaud sbort pitch, whose recoil is 100 per cent. We think the detractors of the belix bave not understond this condition.

storid this condition. to us thit the heiicopteron sys tem bas indeed but little ruture before it, becouse of the extreme lightness that it would he necessary to give the immense structures whose every part would be in motion. Besides, we may ask, What velocity would we obtain, since we would bave bere only one means to employ-that of inclining the rotary axes of the belices? To make use of secondary belices would evidently be a complication as compared with the use of the aeroplane. What also would be the relative immobility of the car suspended from the axes of two lelices revolving in opposite directions? These questions are not as yet answered.

Mechanical Birds.-The imitation of nature must bave always seemed to man as the most ratinal means of artificially solving the problems that she herself bas worked out, and we

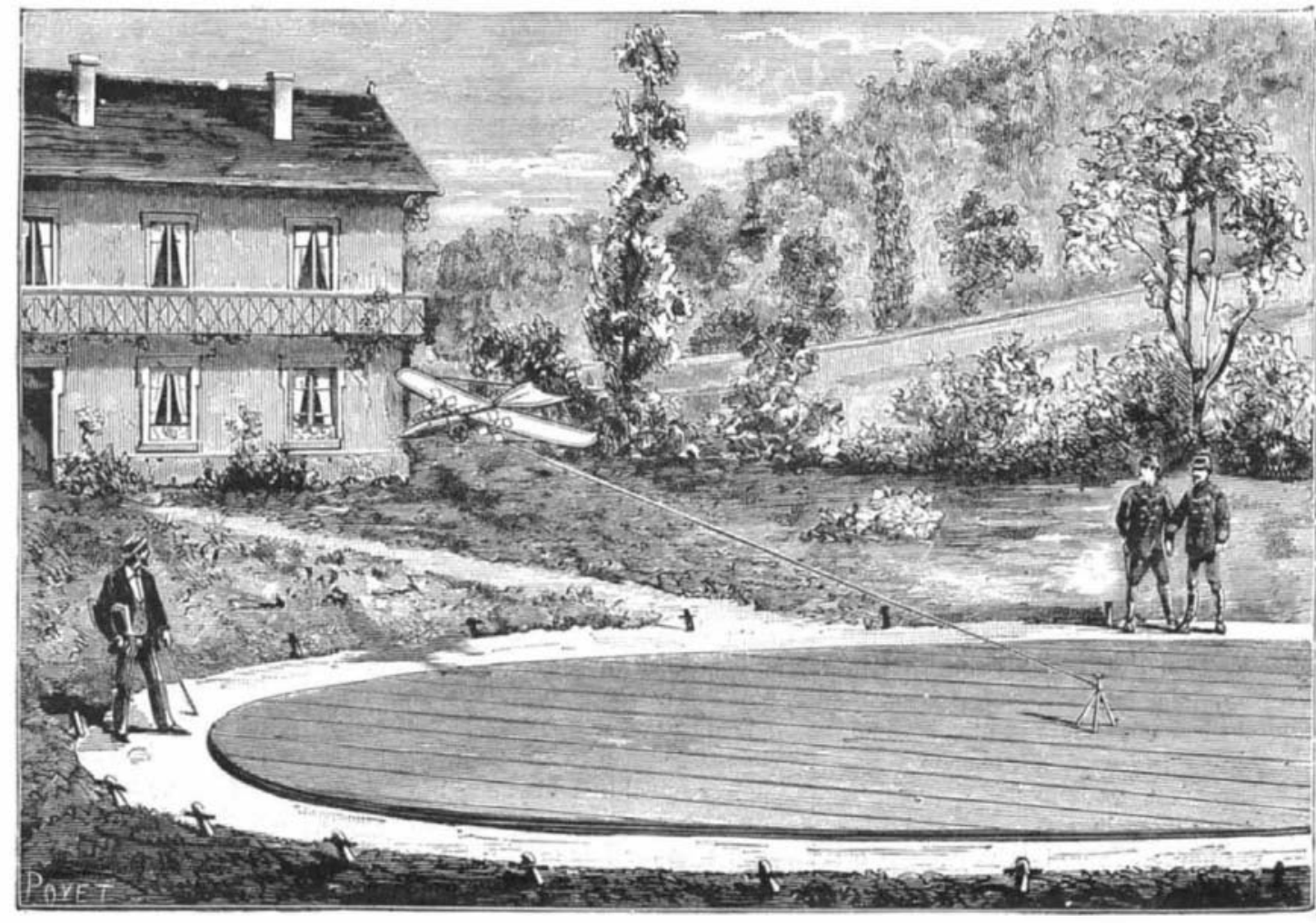

Fig. 3.-EXPERIMENT AT CHALAIS-MEUDON. definitely devoted bimself to the use of the aeroplane as the most capable method of giving practical results, we were still engaged in constructing apparat us based upon the imitation of the flight of birds. Our eyes were finally opened to the evidence, and we entered a path which since then we bave not ceased to follow. We soon congratulated ourself upon this change, for, from the very time of our first trials, the results have been satisfactory.

A small aeroplane of about 0.7 square meter surface was actuated by two belices that revolved in opposite directions. The motor was a compressed air machine analognus to a steam engine, whose boiler was replaced by a relatively large receptacle of 8 liters capacity. Despite the little weight that we could dispose of we were, nevertheless, enabled to give the receptacle sufficient strength to cause it to resist, on trial, more than 20 atmospberes (in our experiments the pressure never exceeded 7 ) 
grammes. The little engine, which develoned a motive power of about 2 kilogrammeters per sec ınd, weighed 300 grammes. Finally, the total weight of the apparatus, animsls naturalists wbo described reptiles as crawlin mounted upon rollers. was 1.75 kilogrammes. This en- expressed bad they known the strange creatures whose bis-

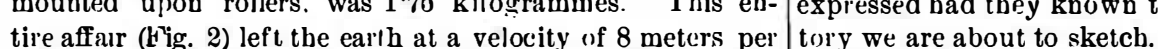

secrivd, altbough the resistances were almost equal to those These animals, which are designated as ornithoscelians or due to the opening of the angle formed by the planes above dinosaurians, partake, by certan characteristics of their or-

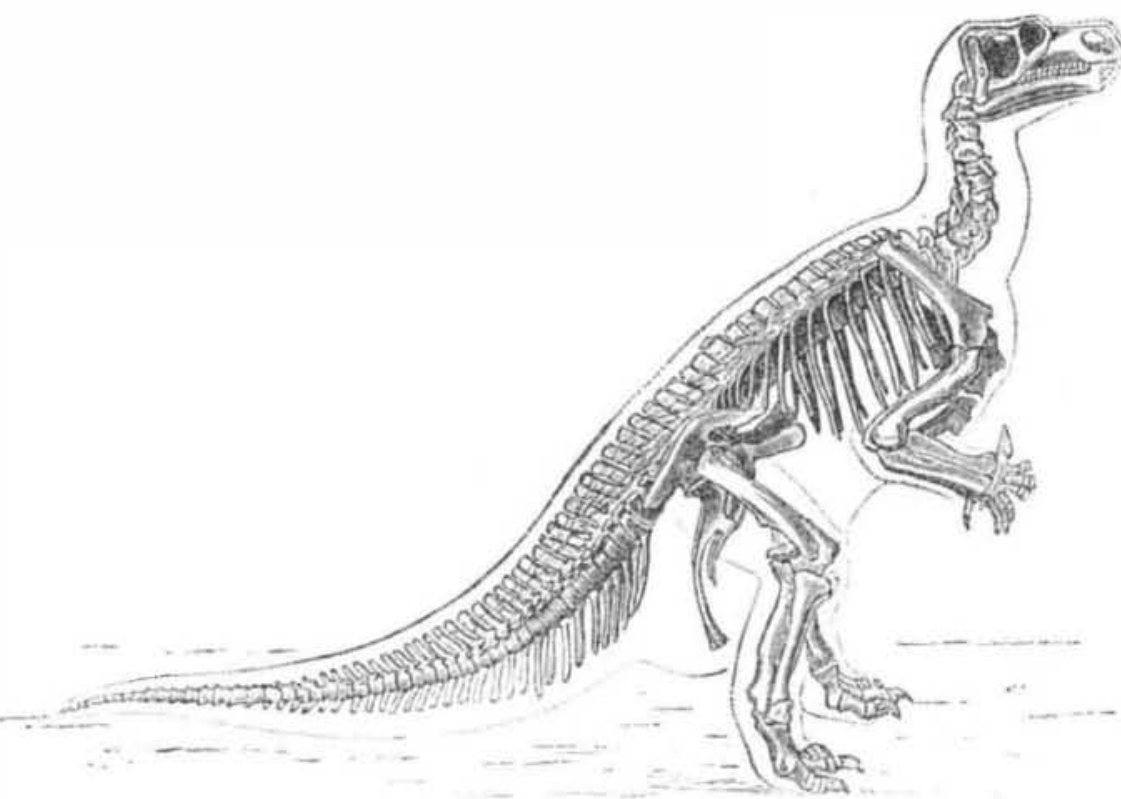

Fig. 5.-SKELETON OF IGUANODON. ganization, of the nature of mammals, birds, and reptiles properly so called, while at the same time exbibiting characters that are proper 10 themselves. They seem to bridge over the gap which in present nature separates the most perfect of the reptiles, the crocudiles and the tortrises, from the lower mam mals - t be marsupials-a nd from such birds as the osThey are so far removed from the repliles that we have to form a distinct subcliss for them equai in value to that which is admitted for reptiles of the present time.

The differences that they present from our reptiles are much greater than those that we find between tortoises and serpents, for example, to merely cite the two extreme terms of the series. We know trich, emu, and cassowary.

as regards form, with those of a lizard of the present time called the iguana. Since that epocb, and especially since a ew years back, our knowledgeconcerning the dinosaurs bas peculiarly increased, and we are beginning to get a glimpse, among these animals, of very different types, which indicate orders just, as distinct as are those of the pachyderms, ruminants, and carnivora among mammals.

Upnn the sides of the Rock.' Mounlains, in the United States, we find strata which can be followed for several bundred miles in extent, and which bave yielded for the inves. igation of paleontologists a small marsupial, remains of fishes, remains of pterodactyls, crocodiles, and tortoises, and fishes, remains of pterodactyls, crocodiles, and tortoises, and
especially an enormous quantity of bones of gigantic dino-

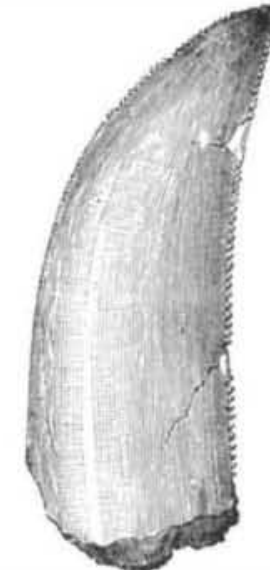

Fig. 1.-TOOTH OF
MEGALOSAURUS.

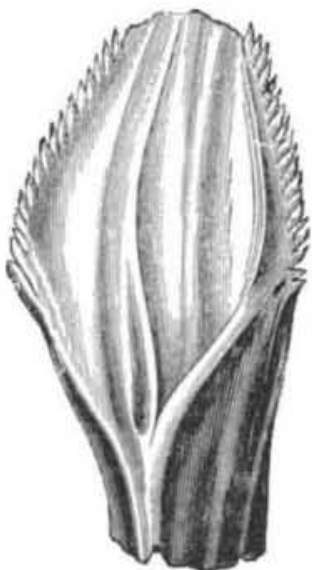

Fig. 2.-TOOTH OF
IGUANODON.

the borizon. The experiment was performed in 1879 at l he $\mid$ nothing of the dinosaurs except their skeleton. It is proba- saurs. We bave here a true bone yard in which lie burjed, Chalais-Meudon Military Establisbment. The aeroplane, ble that if it were permitted us to know what their organi- pellmell, the most curious and strange forms of all the which was at tached by a cord to the center of a circular zation was, how their circulation was effected, and what animals that the ancient ages have bequeathed to us. It is flooring, revolved around the trick, rose from the ground, their mode of development, was, we should not besitate to put to the admirable researches of Marsh and Cope that we owe and once, even, passed over the head of a spectator (Fig. 3). them into a class intermediate between that of the mammals our knowledge of a fauna that bas entirely disappeared. We can only renew bere the thanks that we bave already ad- and birds and that dressed in Messis. Renard and Krebsfor their extreme olslig- of the reptiles proingness and the interest which they appeared to take in our perly so called. It experiments.

was along toward

After this result we formed a project of studying with 1820 that Gideon this apparalus the advantages or disadvantages convected Mantell found the with the use of more or less extended planes, of more or less first bones of dinoopen angles, and of different velocities in the two cases; but sauriansin the midst our resources, which were then more than exbausted by these of 'Tilgate forest, on long aud costly labors, did not permit it, and, to our great the Isle of Wight, in regret, we bave since bad to content ourself with indicatiug strata which are re the programme of our experiment, without carring it out ferred to the lower ourself.

portion of the Cre-

The experiment which we have just described confirmed taceous formation, our previsions, however, and we think that we are now able to and which are tertrace the principal lines of an aeroplane without fear of com- restrial and fres

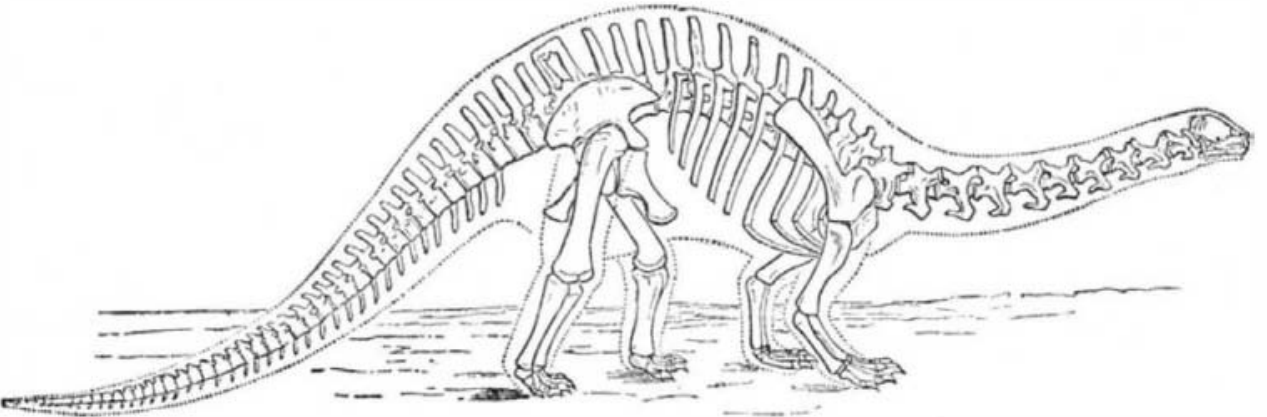

Fig. 4.-SKELETON OF BRONTOSAURUS $(\times 1-125)$,

mitting a grave error. In an aeroplane, as iu a balloon, the water ones that mark a transition from the Jurassic to Guided by the two great laws of correlation of forms resistance to a forward motion increases as the square of the the Cretaceous. Tbese bones, which were very incomplete, and subordination of characters-laws which we owe to velocily. The motive power, then, will here also bave to were referred by Mantell to an animal of great size, which he the incımparable genius of Cuvier, and which, like Ariincrease as the cube of such velocity; but since, for a given lcalled an iguanodon, as the teetb offered certain analogies. [adne's thread, permit us to find our way in the inextricaangle that is supposed invariable, the sustaining thrust and the resistance to motion will always be in the same ratio, the disposable weight will increase with the square of the relocity, so that, as regards this point, we will be more favored than by the use of ballonns.

It must be remarked, per contra, that, with the aeroplane system, large constructions will merely offer the advantage of permitting us 10 obtain motors that are relatively lighter and more economical.

It is very evident that the first essays made with aeroplanes would be only of short duration. Let us at first have modest views. Let an aerial machine work only an bour, balf an bour even, at a velocity of 15 meters per at a velocity of 15 meters per second, and the progress
made will be immense; one may even say that the problem will be entirely solved. After this first step will rap. idly come the improvements that experience will indicate. New motors will become an object of researches that will soon prove fecund, and bumanity will finally find itself in possescion of the most powerful engine that it bas ever imagined. - La Nature.

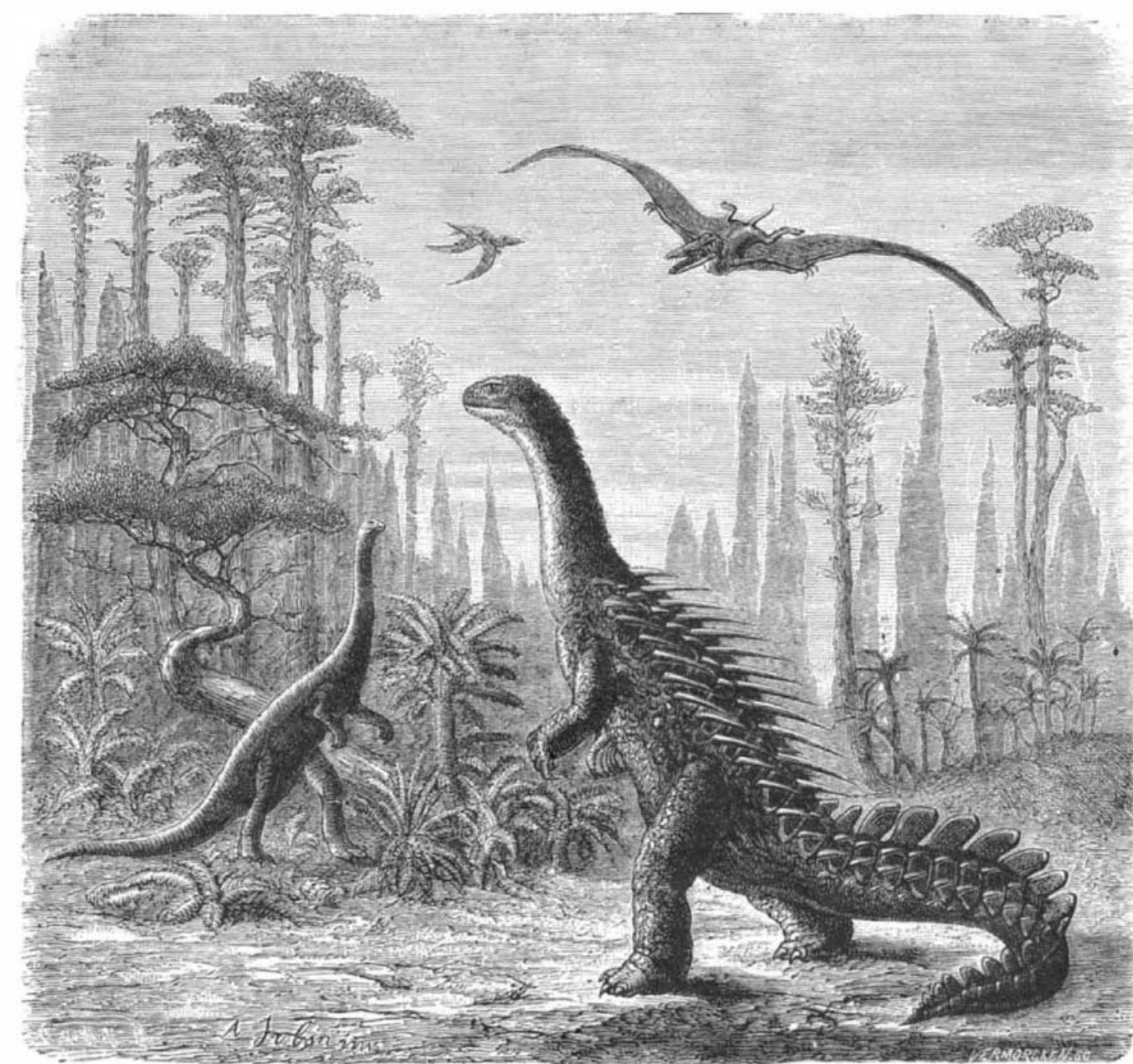

Fig. 8.-AME.jICAN LANDSCAPE OF THE JURASSIC EPOCH WITH REPTHES AND PLANTS OF THE PERIOD. ble labyrinth that is presented by the forms of extinct animals-these two learned A merica a paleontologists bave evoked an entirely new world, and brought up before us the evidences of a fauna of which nothing in existing nature could have given us the least notion.

During the secondary epoch the dinossurs lived also in Europe and in Southern Africa, where they were represented by very diverse types, as has been shown us by the learned researches of Mantell, Oren, Pbillips, Huxley, Seeley, Hulke,Dollo, and Matberon.

Very recent researches bave thrown an entirely new light upon the organization of these animals, and permitted of as complete a study of their skeletons as could bave been made of those of animals now living. We can grasp the general features that connect them with other reptiles, and the peculiar ones that distinguish them from each otber.

What essentially separates the dinosaurs from all ot ber reptiles is that the sacrum is al ways composed of more than two vertebræ, which form a very solid, single bone like Ibat of mammals. These verte. bræ, which exceed the normal number of two, are candal ones that are modiffed so as to serve as a support of the pel- 